\title{
(The Hidden City) Between the border and the vacuum: the impact of physical environment on aspects of social sustainability
}

\author{
E. Douvlou ${ }^{1}$, D. Papathoma ${ }^{1} \&$ I. Turrell ${ }^{2}$ \\ ${ }^{1}$ School of Architecture, University of Portsmouth, UK \\ ${ }^{2}$ Environment Centre, Southampton, UK
}

\begin{abstract}
"...the city is saturated with people, their movements; millions of eyes watching the world.... surely the city is well-known?" (Borden et al. The Unknown City: Contesting Architecture and Social Space, MIT Press, pp. 274-275, 2001). In this statement, Pile questions how-and-why particular urban spaces become known and unknown. Implicit within the notion of social sustainability is social cohesion through social interaction, promoting health and well being through security and sense of place. Movement, at different scales, accessibility and connectivity, are vital in order to experience places and interact with people.

This paper examines the way certain areas within a city are segregated or "hidden", as a result of the physical environment that defines them, by creating borders and vacuums, and discusses the results of surveys and movement analysis of local population. The indication is poor interaction between people from, and outside, these areas, as well as spaces that become "unfamiliar places". Those identified border vacuums then become more than physical boundaries; they define the existence, and therefore aspects of the social sustainability, of whole communities.
\end{abstract}

Keywords: social sustainability, physical environment, border vacuums, hidden city.

\section{Introduction}

There are many concerns today about the environmental impact of our lifestyles and activities and how this can be mitigated. However there is little emphasis on sustainability in social terms. Is an area safe? Well connected to other areas? 
Does it meet the people's needs in terms of facilities? Are those facilities accessible to the community?

An important concept at the core of the notion of social sustainability, is the "sustainability of community", which is concerned with the continuing viability and functioning of society as a collective entity. Bramley et al [2] analysed the interactions between social sustainability and urban form, and suggested that sustainability depends upon several aspects of community and neighbourhood life, which include (i) interactions in the community/social networks; (ii) community participation; (iii) pride/sense of place; (iv) community stability; (v) security (crime).

Hanson and Hillier [3] noted, "that the urban environment is the physical embodiment of organised human culture and practices". Therefore, perhaps by analysing the way people interact with their immediate urban environment - "the physical embodiment"- and consequently with each other, we can gain incite into aspects of social sustainability. If the urban environment is designed in a certain way, does this induce or encourage the community to act or being perceived in a certain way?

The paper focuses on the research in two areas in the city of Portsmouth, UK, using Jacobs' concept of the border vacuum as an analytical tool. Both areas are characterized and generally defined by natural and man-made boundaries, have two of the highest crime rates in the city and are perceived as deprived areas. The results are based on surveys addressed to local population as well as movement analysis through observation and tools such as Space Syntax. But prior to that, it was deemed important to discuss the concept of the border vacuum.

\section{Border vacuums}

Border Vacuums, a term coined by Jane Jacobs, are possibly one of the most disruptive and influential urban anomalies that appear in our cities. She states: "a border - the perimeter of a single massive or stretched out use of territoryforms the edge of an area of 'ordinary' city. Often borders are thought of as passive objects, or matter-of-factly just as edges. However a border exerts an active influence" [4]. Highlighted in these areas of active influence are railway tracks, busy roads and highways, and large institutional and industrial premises, and areas of a large single use. Of these railway lines are thought to be the most disruptive.

These borders often represent a significant part of the community. They are viewed, in affect, as barriers, which restrict movement in, out and through that zone. Some grounds such as military uses create a completely impermeable boundary to non-authorized public. This effectively cuts one part of the city off from another and limits the routes in and out of that community. If this is present too often within a community it could be said that the urban environment can become claustrophobic, squeezed with no way of escape to release the pressure. Also most of these vacuums are places, which are not used at night. Railways, universities, military and school playing fields, and large industrial areas all become dormant at night. This allows them to become conduits for crime from 
other areas. Either people moving through them to escape the police or using them as the spatial domain for illegal activities, and as with railway tracks it is often the areas lying next to or near these areas which suffer the most from the affects.

There are natural borders, of course - rivers, beaches, and lakeshores. These, however, because they can be beautiful or recreational, are often assets. The borders that cause most damage, however, are manmade. Freeways, for instance, are like having a river in that they can only be crossed in certain places, and they mark a definite end to any neighbourhood. Unlike a river, though, nobody wants to come take a walk along the freeway.

\section{Case study areas: physical qualities and social characteristics}

The two case studies researched are both located in the city of Portsmouth, UK (Figure 1). Although the case studies were chosen as part of two independent researches, they share some common characteristics. Portsea was one of the first areas to be developed on Portsea Island for use as a port and dockyard.

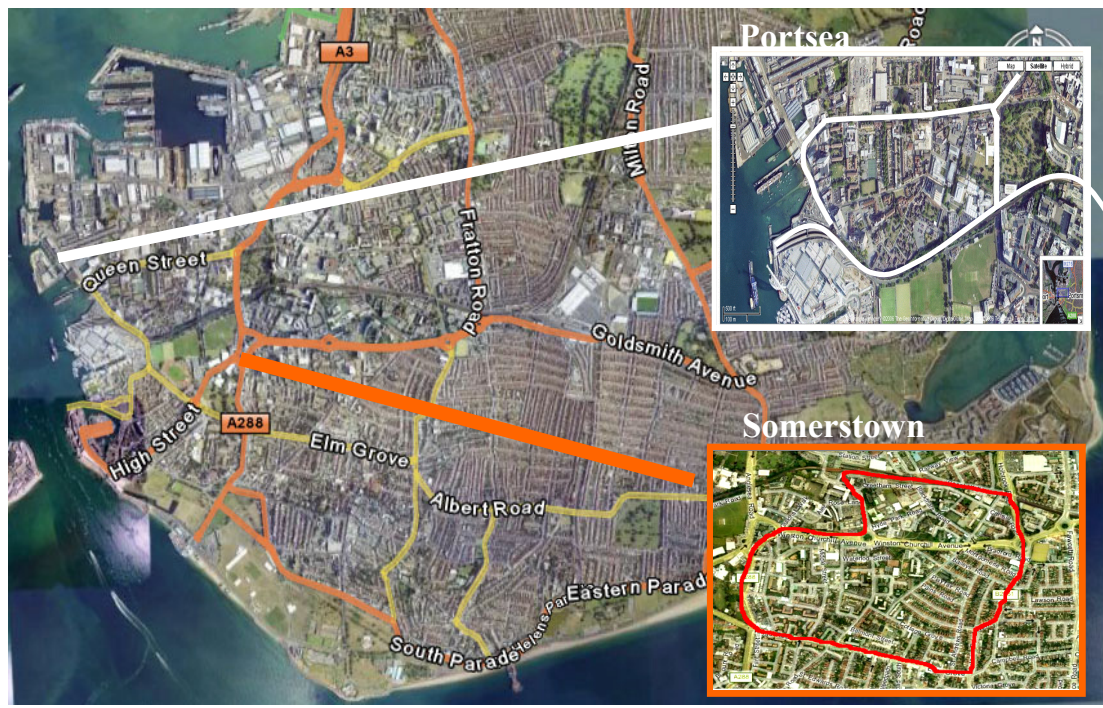

Figure 1: Map of Portsmouth and location of the two case study areas, Portsea and Somerstown (source: Google Earth).

Portsea was, and still is, home to the Royal Navy and was once home to heavy industry such as shipbuilding, a busy dockyard and a brewery. Although the navy controlled until recently much of the land in the area, what was left was used for high-density terraced housing. Throughout the 60's and the 70's industry and employment in the dockyards was drastically reduced. Recently more development has occurred in the area on old MOD land. Today, the 
majority of buildings in Portsea are residential, mainly consisting of social housing. As it can be seen in Figure 2, it is clearly defined by the Historic Dockyard and the MOD land (Navy) to the north, the sea and a transportation hub that limits access to the shoreline to the west, as well as Gunwharf Quays, a new development of housing, shops and entertainment facilities. The railway line defines the border in the south and a series of University buildings to the east. Despite the fact that the uses that border Portsea provide some of the most significant attractions and income to the city, the area remains socially and physically isolated from the city as a whole. It has one of the highest levels of deprivation in the United Kingdom, despite being central to Portsmouth, and crime levels are several times the city average. Unemployment is quite high and the residential value of the houses are just $1 / 3$ of the houses and flats in the adjacent new development of Gunwharf Quays.

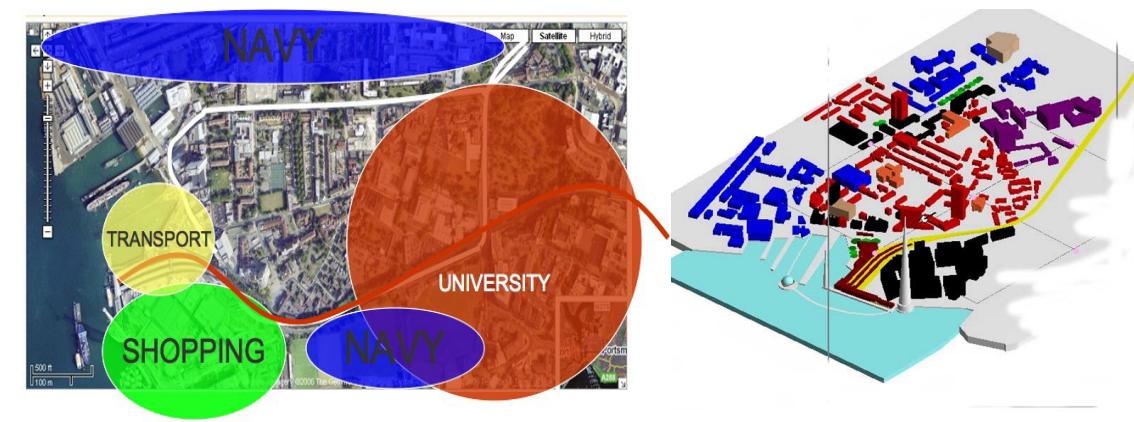

Figure 2: $\quad$ Portsea "under pressure"; the uses of land and transportation lines that define Portsea's boundaries (left). To the right, a virtual representation of Portsea, highlighting the different uses of buildings in the area (housing is located in the centre of the model).

The historic development of Somers town -the second case study area- and North Southsea is a direct result of the growth of the dockyards and the seaside resort of Southsea. As the dockyards expanded, in particular during the late 18th and the 19th centuries, the ribbons of terraced streets grew dramatically. Somers town is a result of the late nineteenth century expansion. Much of the historic structure of the area has now been lost, in part due to World War II bombing campaigns over the city, but largely through post-war redevelopment. Many of the historic street connections have now been severed, isolating most of the area from the rest of the city. This approach was planned to reject the principles that had driven the development of towns and cities for many centuries. The area is an integral part of the "Heart of Portsmouth" bid for UK government Single Regeneration Budget (SRB) funding and a Joint Project Board has been established to oversee the preparation of a new physical regeneration plan through continued community involvement [5].

As previously discussed, heavy traffic routes such as avenues and railways create boundaries that subsequently affect the local community and the adjacent 
areas. The construction of Winston Churchill Avenue (Figure3) in the 1960s, divided the area into two major parts: the northern part of Somers town, which is bordered by Winston Churchill Avenue on the south and a major railway on the north which is the main station in Portsmouth in its city centre. The second largest part to the south of Winston Churchill Avenue is defined by a series of residential Victorian houses to the east and west and a lively, street to the south with shops, restaurants and residential buildings. When passing through Somers Town, the street sinks below grade and has no pavements, effectively dividing the community in two and removing its geographical heart. It is a street that has turned its back on the community, rather than joining its two halves together, effectively hollowing it out. Residents and non-residents alike have no reason to use the street. Moreover, the emptiness and isolation of the street have come to characterise the community district, which is defined in terms of the railway to the north - another impossible barrier. To the south, the area is defined in terms of streetscape: the southern boundary is a fuzzy line where the traditional houseand shop-lined streetscape is replaced by a confused maze of walkways and spaces, randomly punctuated by tower blocks and blocks of maisonettes. In a manner similar to that described by Firey [6], since its construction, the area and the community living in it have developed a reputation of being socially disadvantaged, which has further discouraged visitors and even prospective residents. The poor reputation of the area has created a cycle of pernicious decline, in which the reputation discourages inward visitors and investment, which in turn worsens the economic and social conditions in the area.
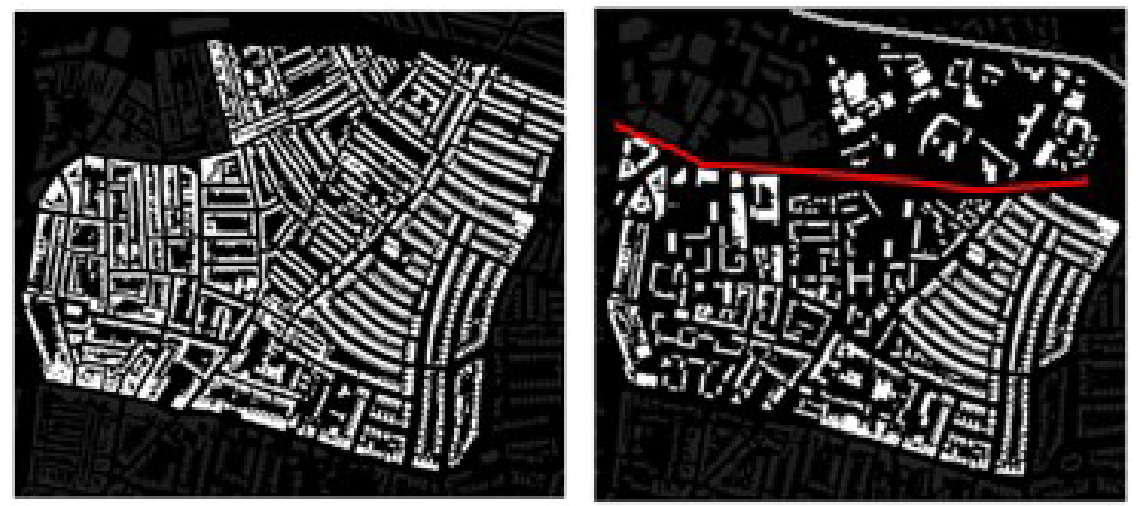

Figure 3: The ground figure maps above show the area of Somerstown before (1910) and after (2007) the construction of Winston Churchill Avenue (source: City Council).

\section{Survey results}

For each of the case studies a survey was addressed to the local population related to the following topics: preferred routes to access facilities (work/home/schools/recreation facilities/surgery/institutions/etc), reasons for 
preferred routes, frequency of use of preferred and less preferred routes, means of movement/transportation, safety, use of public open spaces, range of facilities that need to be accessed, personal information (age/gender/education/type of accommodation). The compilation of the data was also supported by observations in situ of the local population. The questionnaires were targeted to local people, however, external interviewees provided an insightful range of information that relevant to the way each of the local population in the two case studies interacts with the rest of the city. The information was collected during one calendar month in 2007. In Portsea 85 local resdients out of apopulation of 1650 (2001 census) and 30 external interviewees were sampled. In Somerstown,

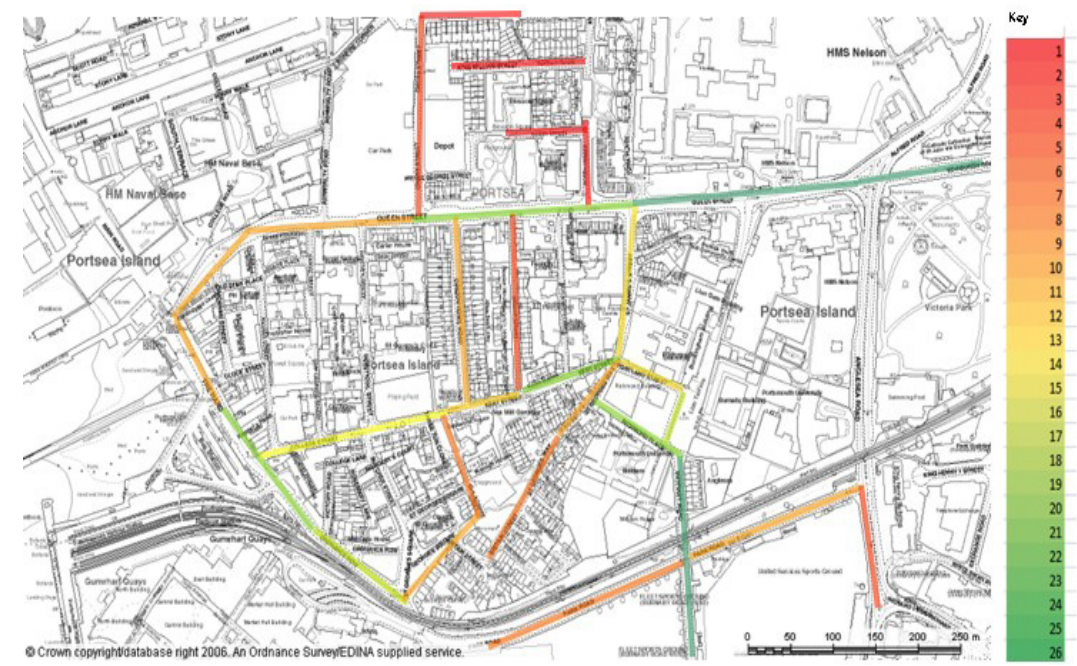

Figure 4: Map showing the amount of times a route is regularly used by pedestrians.

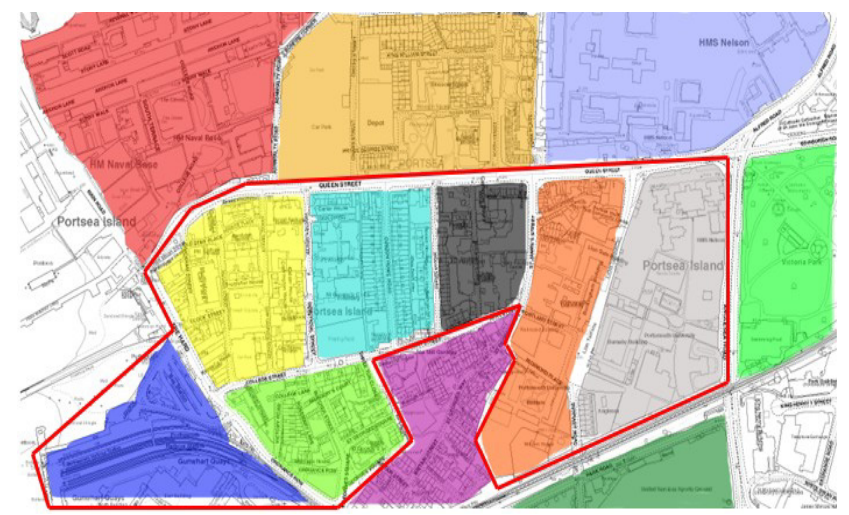

Figure 5: $\quad$ Map showing designation between areas of perceived high and low threat within the case study area. 
113 individuals were sampled (out of a total population of 9320, 2001 census). Every time "space" is mentioned, it is always related to human activity; the use of space, interaction, density, accessibility and so on.

Figures 6 and 7 demonstrate results for the Portsea area [7]. Generally, the areas within the line could be described as having a lower level of perceived threat than the areas outside. Correlated perfectly to Jane Jacob's concept of border vacuums, the areas identified as areas of higher danger are segregated towards either the railway lines or the two main roads. The exception is the zone that lies within the main conurbation and is not segregated by any main infrastructure from the main part of the urban construct. As Jacobs states "the places that do worst of all, physically, are typically the zones directly beside the track [or other vacuum] on both sides" [4]. The zone is the only one that is directly impacted by two different border vacuums; the railway and the University of Portsmouth campus. This seems to be having a detrimental affect on the area. The majority of interviewed considered the area separated from the main section of the conurbation by Queen Street the most unsafe. It has already been described as a piece of infrastructure that has high use by both pedestrians and vehicles, however the research indicates that this section of the community is isolated from the rest of Portsea as a whole. This zone is also fronted by large areas of single use on its east and west sides.

It should be highlighted that, areas of limited or no access, have been identified as areas of threat. This may be a response to the unknown nature of the areas, the unfamiliarity of space, the inaccessibility of the place. However, this brings to mind the work of Newman [8] on Defensible Space, in which he noted that cul-de-sacs, traffic free streets, streets without shops, and streets which are not overlooked by houses are often unsafe, and perceived as being unsafe.

Similarly structured, is the analysis of the results from data collected from Somerstown [9]. Figure 6 represents the built environment, with different colours indicating the various functions that the buildings have. However most of the area consists of accommodation buildings. The eastern and central area comprises mostly of houses except a few religious and trade buildings existing. The southern area has a much more diverse range of activity, such as trade (minimarkets), entertainment (pubs, restaurants), education (school and library) as well as houses. The north west area is mainly of university owned buildings, as the rest is mostly houses and businesses on the edges. The central part is only housing and the northern except the accommodation type of buildings has a few schools including a driving one.

Planners and designers often use a tool kit of evidence based methods to assess connectivity. Space Syntax is one of these. Using Space Syntax [10] in Figure 7 connectivity routes are displayed. The red colour symbolizes the most connected routes and the blue ones the least connected. Green lines are considered to be transitional. As it can be seen the red and subsequently most connected line is Winston Churchill Avenue. The next most connected route is a north-south axis road, with the light green colour, and then the road which is joined by the traffic lights on Winston Churchill Avenue. The majority of blue lines are dead ends and routes, which are not connected with other lines, 


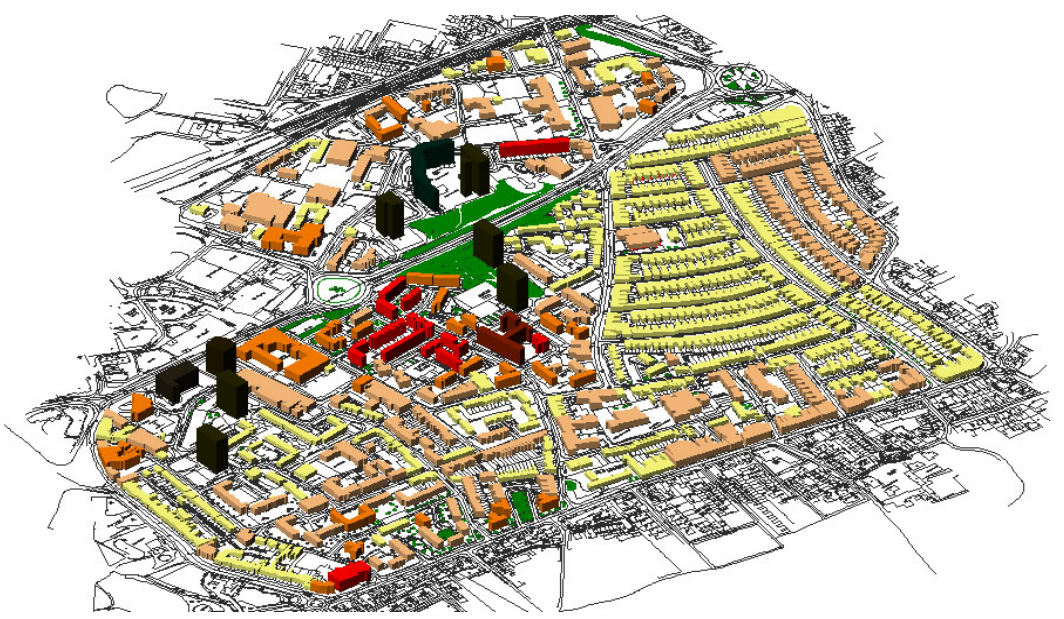

Figure 6: Map showing the amount of times a route is used by pedestrians regularly (lighter colour indicates medium use).

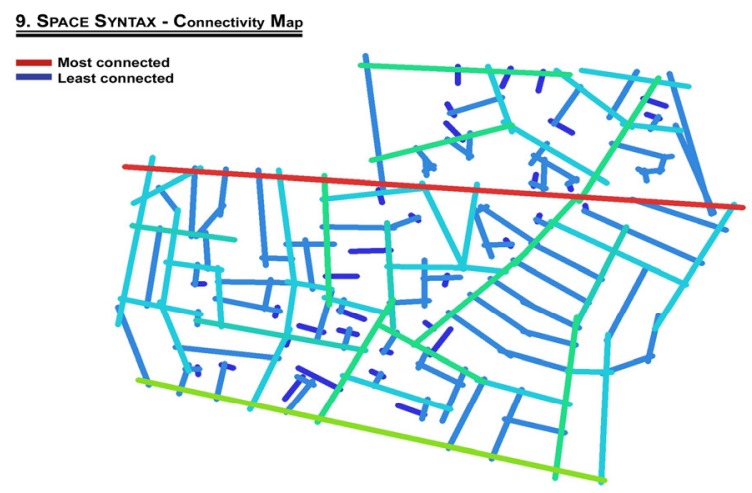

Figure 7: Connectivity routes for Somerstown generated with Space Syntax.

indicating poor connectivity in the area. Most of the dark blue lines do not provide more than two or three different routes, indicating there are no variety of choices to pedestrians and vehicles. However, while Space Syntax does well at indicating routes with poor connectivity, the classification of Winston Churchill as a route of high connectivity is misleading. Observations showed that the street is used heavily by car and cycle traffic but not by pedestrians. This can be seen more easily in Figure 8. Here, each dot represents ten people using each of the routes in either direction, for morning and evening hours respectively. As can be seen the pedestrian and cyclist movement during the day is intense in most of the area and routes. However, the inner parts of the central and north area are not preferred routes. The movement once more is greater on the heavy traffic routes around the site and the eastern area. Thus, while mechanical methods of assessment such as Space Syntax can be useful, they should be supplemented by on site observation. 

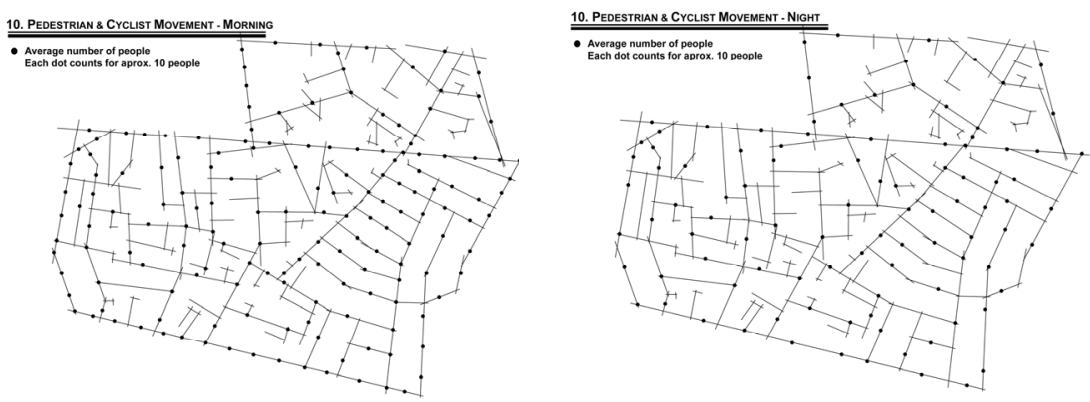

Figure 8: A virtual representation of Somerstown; light coloured buildings indicate housing, whereas darker colour signifies University buildings and all other various functions (shops/leisure).

At night Somers town reveals a different character. The pedestrian movement is limited due to the area's lack of attraction, inaccessible routes, poor street lighting and bad design of open spaces, as well as the bad reputation. Also there are no bus services running during the night, which is rather inconvenient and decreases the number of people going though as well as to the site. Moreover there is no crossing between the northern part and the rest of the area and this way it remains isolated encouraging criminal behaviours to happen along the heavy traffic avenue on both sides as well as in Victoria Park area [5].

The results above correlate well with people's perception of the area, as well as observation and monitoring of existing conditions. Again, in keeping with Newman's findings, one of the key issues highlighted by the walkabouts was the community safety, especially "fear of crime" resulting from perceived "hostile areas", that make the users feel unsafe, such as pedestrians and cyclists. This is usually due to sparse pedestrian or vehicular use, a lack of natural surveillance from overlooking properties or poor street lighting. Most of the streets are edged by tall buildings with no ground floor activities, or parking areas, and few entrances are orientated towards the streets. The area is largely inaccessible to vehicles, and the central parts are accessible only for pedestrians and cyclists. The well-located rail links offers good and convenient services but the railway creates a physical barrier and its only crossing is a footbridge for a distance of $200 \mathrm{~m}$. Bus services run only during the day, and that raises other concerns such as insecurity. Additionally in terms of accessibility it is of great importance to mention that the northern part is totally disjointed with the rest of the area as the only crossings, between the two major parts, are approximately $200 \mathrm{~m}$ apart, between the traffic lights on Winston Churchill Avenue (Figure 9), limiting the pedestrian access and permeability.

\section{Conclusions}

The current paper provides an opportunity to interrogate the seemingly strong link between the physical environment and the society that is contained within it; 

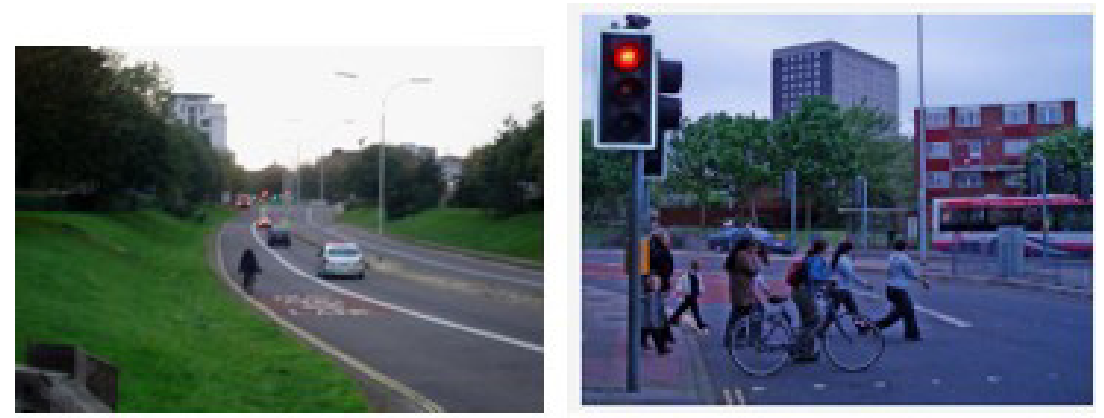

Figure 9: Crossings in Winston Churchill Avenue, Somerstown, Portsmouth: authors.

the social - urban relationship. As Phillips [11] noted "The city is a vast and complex system which in turn is part of an even bigger system of social organisation".

Research in the form of surveys, observations and monitoring of existing condition was undertaken in two case study areas in the city of Portsmouth. Both Portsea and Somerstown are defined by a form of natural or man-made border such as heavy traffic streets, railway line, the sea and large areas of single and often of restricted use. Linear borders such as heavy traffic streets are permeable, however, in the case of the railway line, access and movement through it is more difficult. Both the latter as well as large, single use areas, such as the University and the Navy grounds and open areas surrounding tower residential blocks create "border vacuums". Areas close to, or surrounded by border vacuums are poorly used and with certain degree of fear and uncertainty from the local population whereas population outside the local community consciously avoid these areas.

Conversely, areas with greater pedestrian movement allow and encourage social interaction and by that implicitly contribute to surveillance, increase sense of security and consequently community interaction.

The results from observation and space syntax analysis discussed, indicate poor connectivity in most parts of both areas, a disconnection in physical terms, which not only acts negatively in engaging each area from other facilities in the city and community members, it also disconnects the area from the system of organisation and control. Disconnection from the systems of control and management suggests that these areas are prone to crime, physical degradation and ultimately a low level of sustainability.

Both Somerstown and Portsea are currently the focus of replanning exercises by Portsmouth City Council. Residents have been extensively consulted to determine their preferences and how they use the areas. A jet factor in any regeneration scheme must be to transform the border of Winston Churchill Avenue into a "seam" which links Somerstown with the rest of Portsmouth, and as well, to remove the sense of an "edge" as a boundary or border, to use Lynch's term [12], making it an entrance. This would involve changing the reputation of the area. As Ryder [13] noted, a poor reputation of an area can deter investment and regeneration despite the potential for growth and renewal. 
Interestingly, as part of the Portsea regeneration, a new residential area is being built on the site of a former brewery - the Admiralty Quarter. The site backs up against the naval base, and the site plan is not dissimilar to that of the area directly to the north, which was considered one of the least safe areas in Portsea. However, planners seem to be confident that this plan will "work". By contrast, much of the existing housing in Somerstown and Portsea is council owned, and rented rather than owned by residents. Further research is needed, but some, following Newman [8] would suggest that a sense of ownership or control is also fundamental in fostering sustainability, and that management, control, and a sense of being a recognised stake holder are at least as important as physical design in promoting neighbourhood social sustainability.

\section{References}

[1] Borden, I., Kerr, J., Rendell, J., Pivaro, A. The Unknown City: Contesting Architecture and Social Space, MIT Press, pp.274-275, 2001

[2] Bramley, G., Dempsey, N., Power, S. and Brown, C., What is "Social Sustainability" and How do our Existing Urban Forms Perform in Nurturing it? "Sustainable Communities and Green Futures" Conference, Bartlett School of Planning, University College London, London, 2006

[3] Hanson, J., Hillier, B., The Social Logic of Space. Cambridge: Press Syndicate of the University of Cambridge, 1988

[4] Jacobs, J., The Death and Life of Great American Cities. London: Pimlico, 2001 (original edition 1961)

[5] Somers town, Portsmouth: City Council, 2006

[6] Firey, W. American Sociological Review, Vol. 10, No. 2, 140-148. Apr., 1945

[7] Turrell, I., Cities on the Edge: The social-urban relationship and the measurement of sustainability, MSc Thesis, Architecture and Environment, School of Architecture, University of Portsmouth, 2008

[8] Newman, O. Defensible space. People and design in the violent city. London: Architectural press, 1972

[9] Papathoma, D., Urban transformations in Somerstown, MSc Thesis, Architecture and Environment, School of Architecture, University of Portsmouth, 2008

[10] Space Syntax, http://www.spacesyntax.com/

[11] Phillips, C. Sustainable Place. Chichester: John Wiley and Sons Ltd, 2003

[12] Lynch, K. (1960). The image of the city. USA: The M.I.T. press

[13] Ryder, A. "The Changing Nature of Adult Entertainment Districts: Between a Rock and a Hard Place or Going from Strength to Strength?", Urban Studies, Vol. 41, No. 9, 1659-1686, 2004 